\title{
Rekomendasi Guest House dan Villa Kota Wisata Batu Berbasis Android Dengan Metode Profile Matching
}

\author{
Rizky Irwan Saputra ${ }^{* 1}$, Gita Indah Marthasari ${ }^{2}$, Wildan Suharso ${ }^{3}$ \\ 1,2,3 Teknik Informatika/Universitas Muhammadiyah Malang \\ Riizkyiirwan@gmail.com ${ }^{*}$
}

\begin{abstract}
Abstrak
Bisnis Penginapan Villa dan Guest House di daerah Pariwisata seperti Kota Batu telah menjadi satu industri yang memberikan hasil yang besar untuk suatu daerah. Sehingga objek Penginapan perlu dikembangkan untuk mendapatkan hasil yang lebih maksimal. Ada berbagai pengaruh dari perkembangan Penginapan Villa dan Guest House, salah satunya adalah perbaikan ekonomi dari warga sekitar tempat. Kota Batu merupakan salah satu kota yang memiliki berbagai pariwisata dan menjadi tempat yang populer untuk dituju oleh masyarakat yang tinggal didaerah Jawa Timur khususnya. Akan tetapi, wisatawan seiring kebingungan mengenai masalah penginapan dari mulai harga, jarak tempat wisata dan fasilitas. Keputusan rekomendasi Penginapan Villa dan Guest House dilihat dari berbagai faktor, seperti; harga, fasilitas, jarak dan layanan dari lokasi user berada saat ini dalam bentuk maps, fasilitas. Profile Matching merupakan sebuah mekanisme pengambilan keputusan dengan mengasumsikan bahwa terdapat tingkat variabel prediktor yang ideal yang harus dipenuhi oleh subyek yang diteliti, Selain itu untuk membantu dalam penentuan jalur akan digunakan Google API .Untuk Core factor adalah kriteria (kompetensi) yang paling penting atau menonjol atau paling dibutuhkan oleh suatu penilaian yang diharapkan dapat menghasilkan hasil yang optimal sedangkan untuk secondary factor merupakan faktor pendukung yang kurang dibutuhkan oleh suatu penilaian.
\end{abstract}

Kata Kunci: Core factor, Secondary Factor, Profile Matching

\begin{abstract}
Business Lodging Villa and Guest House in Tourism area like Batu City has become one industry that gives big result to a region. So that the object of the Inn needs to be developed to get maximum results. There are various influences from the development of Villa Lodging and Guest House, one of which is the economic improvement of residents around the place. Batu city is one of the cities that has various tourism and become a popular place to be targeted by people who live in East Java area in particular. However, tourists are confused about the issue of lodging from the start of the price, the distance of tourist attractions and facilities. The decision of the Villa Villa and Guest House recommendations is seen from various factors, such as; price, facilities, distance and service from the user's current location in the form of maps, facilities. Profile Matching is a decision-making mechanism by assuming that there is an ideal predictor variable level to be met by the subjects studied. In addition to assisting in the determination of the path will be used Google API. For Core factor is the most important or prominent criteria (competence) or most needed by an assessment that is expected to produce optimal results while for secondary factor is a supporting factor that is less needed by an assessment
\end{abstract}

Keywords: Core Factor, Secondary factor, Profile Matching

\section{Pendahuluan}

Pada aplikasi ini pengguna cukup memberikan referensi ditiap kriteria yang disediakan pada halaman menu di aplikasi ini, hasil yang dikeluarkan dari aplikasi ini berupa urutan rekomendasi berdasarkan kriteria yang diinputkan dan memberikan rute ke hasil rekomendasi tersebut menggunakan Google Map. Agar aplikasi ini dapat berfungsi dengan baik diperluhkan data-data sebanyak mungkin mengenai alamat, fasilitas, layanan dan harga dari jasa guest house dan villa di Kota Wisata Batu, pada data yang berisi alamat akan dibandingkan dengan posisi pengguna aplikasi yang diambil menggunakan koordinat GPS sehingga output aplikasi ini memberi informasi jarak tempuh ke tempat yang direkomendasikan. Metode perekomendasian menggunakan Profile Matching. 
Metode Profile Matching digunakan untuk menentukan rekomendasi guest house dan villa berdasarkan jarak, tarif dan fasilitas yang disediakan oleh penyedia jasa tersebut, alasan menggunakan Profile Matching karena keunggulan dari metode ini dalam memberikan hasil dari perhitungannya yang berupa peringkat dari kriteria-kriteria yang diinputkan dan akan menyeleksi alternatif terbaik dari sejumlah alternatif [1], dalam metode Profile Matching menggunakan Core Factor (NCF) dan Secondary Factor (NSF) sehingga sangat tepat apabila digunakan pada pemilihan berdasarkan keinginan pemakai karena tidak semua parameter yang digunakan atau ditampilkan pada input dari user merupakan faktor utama yang diinginkan pengguna, faktor lain yang mungkin menjadi pertimbangan ditempatkan pada Secondary Factor (NSF), untuk rute atau jalur terdekat yang divisualisasikan dalam bentuk peta menggunakan Google Map API [2] tujuan perancangan sistem ini adalah agar dapat memberi informasi yang jelas dan anjuran yang tepat kepada wisatawan yang ingin berkunjung dan menginap di kota wisata batu.

Pada penelitian sebelumnya yang dilakukan oleh Hafsah dengan judul "Sistem Pendukung Keputusan Penentuan Hotel dengan Menggunakan Metode Promitee dan AHP" menjelaskan bahwa kriteria yang diinginkan oleh user yang menggunakan sistem rekomendasi seperti ini antara lain adalah harga, kelas, lokasi, fasilitas dan layanan [3] sementara pada penelitian yang dilakukan oleh Arisandi "Sistem Penunjang Keputusan Pemilihan Hotel di Kota Kendari Menggunakan Metode Fuzzy" menggunakan harga, lokasi dan kelas sebagai kriteria yang diberikan ke pengguna [4], maka pada penelitian ini penulis menggunakan kriteria berupa harga, jarak dari user aplikasi dan fasilitas yang ditawarkan sebagai parameter yang harus diisikan oleh pengguna.

\section{Metode Penelitian}

\subsection{Block Diagram}

Pada bagaian ini akan dijelaskan mengenai alur dan gambaran program yang bekerja secara keseluruhan, pada Gambar 1 akan memberikan ilustrasi kerja aplikasi dan interaksinya dengan database yang menjadi pusat penyimpanan data.

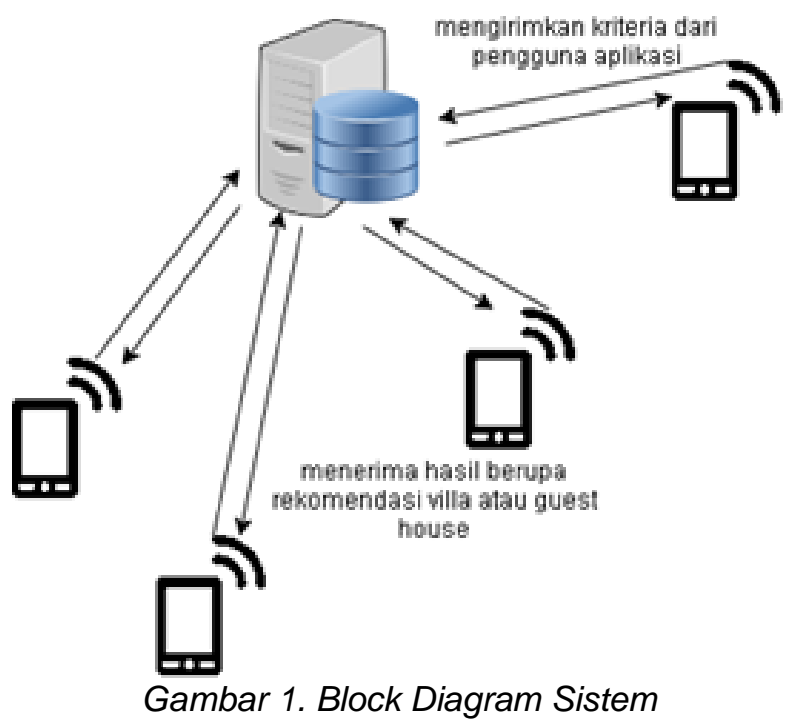

Pada Gambar 1 dijelaskan bila aplikasi ini menyimpan data dari guest house dan villa yang terdaftar dalam sistem aplikasi guest house dan villa di kota Batu, data tersebut diakses oleh aplikasi pada smartphone pengguna untuk memperoleh data rekomendasi yang diproses menggunakan metode Profile Matching dan untuk penentuan jalur terdekat menunju guest house atau villa yang direkomendasikan.

\subsection{Metode Perancangan}

Pada Gambar 2 dijelaskan langkah-langkah yang dilalui oleh penulis sehingga penelitian dapat dikerjakan, dimulai dari observasi masalah yang dialami penyedia jasa vila dan guest house di Kota Wisata Batu, menentukan suatu metode yang digunakan untuk memecahkan masalah dalam hal ini menggunakan metode profile matching, analisis kebutuhan data, penggumpulan 
data dengan wawancara, perancangan kemudian data tersebut diubah kedalam bentuk yang dapat diproses menggunakan Profile Matching untuk kemudian disimpan di database, dari database tersebut program android akan mengambil data untuk diproses dengan metode Profile Matching.

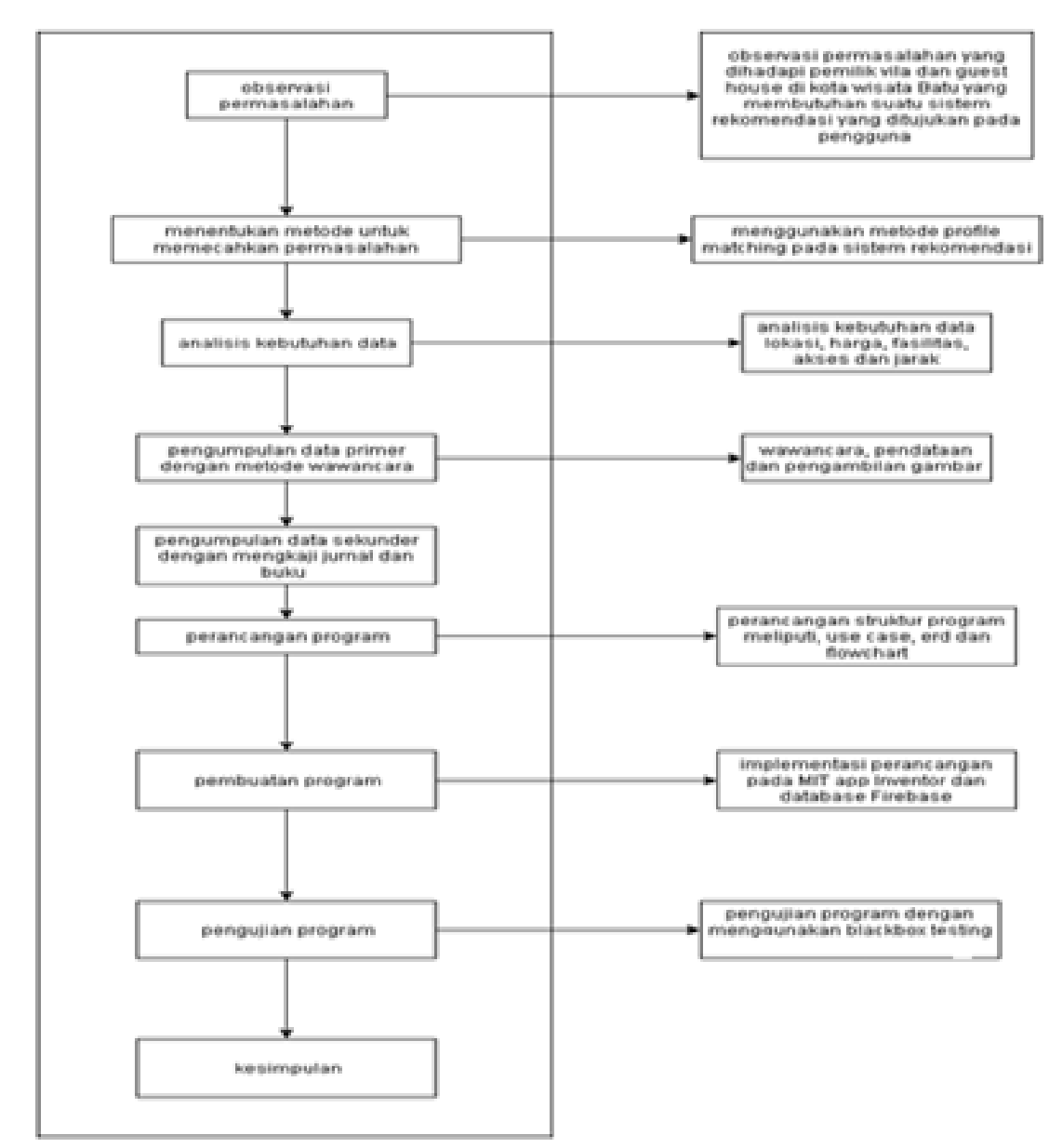

Gambar 2. Alur Metode Perancangan

\subsection{Usecase}

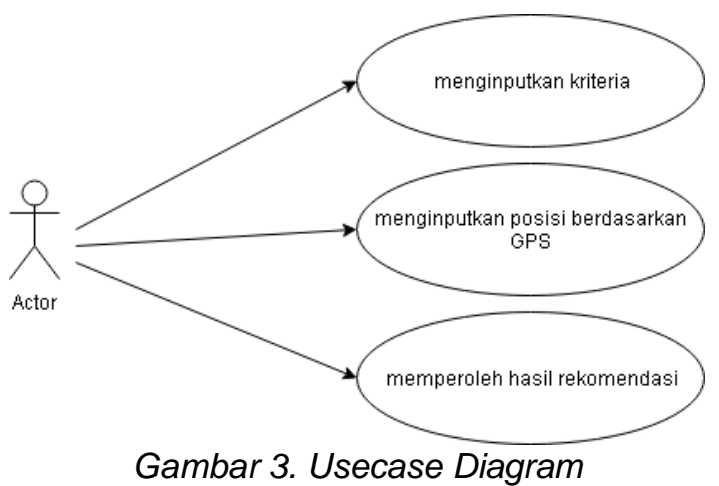

Pada Gambar 3 merupakan usecase diagram yang menjelaskan hal-hal yang dapat dilakukan oleh pengguna aplikasi ini, dimulai dengan menginputkan kriteria yang akan digunakan dalam profile matching kemudian menginput koordinat berdasarkan data GPS kemudian semua input diproses dengan profile matching sehingga pengguna memperoleh rekomendasi beserta petunjuk menuju tempat yang direkomendasikan. 


\subsection{Flowchart Program}

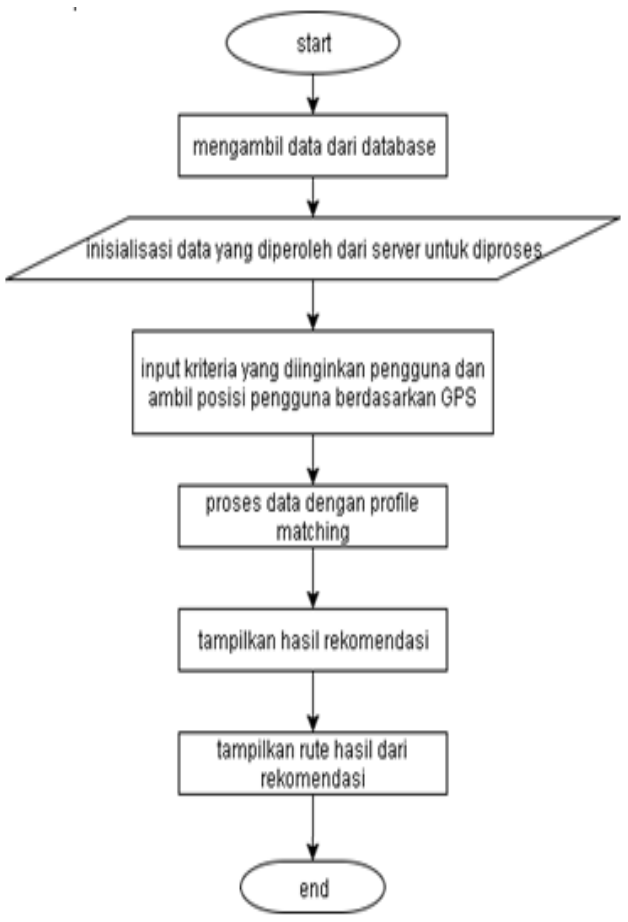

Gambar 4. Flowchart

Pada Gambar 4 merupakan flowchart yang menjelaskan bagaimana alur program yang berjalan dan alur program akan menanyakan kriteria yang dikehendaki oleh pengguna aplikasi ini sehingga dapat disesuaikan ketika pemrosesan menggunakan metode Profile Matching,

\subsection{Profile Matching}

Profile Matching merupakan suatu metode yang mencoba mencari suatu kombinasi terbaik yang sesuai dengan kriteria yang diberikan sebagai acuan pencarian pada sekumpulan data, berikut merupakan gambaran langkah-langkah yang harus dilalui dalam penerapan Profile Matching yang merekomendasikan pemilihan Guest House dan Vila di Kota Wisata Batu [5]. Adapun langkah-langkah yang harus dilakukan pada metode profile matching.

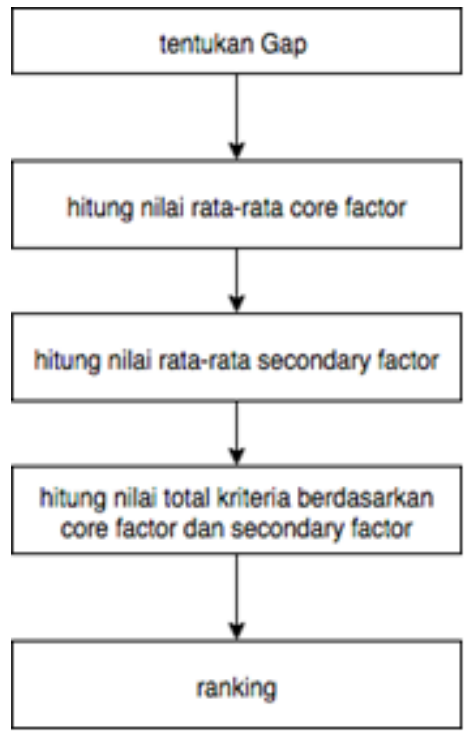

Gambar 5. Runtutan Profile Matching

REPOSITOR, Vol. 2, No. 6, Juni 2020: 691-700 
Pada Gambar 5 merupakan runtutan proses yang dilalui metode profile matching guna memberikan hasil rekomendasi melalui pencocokan dengan gap dan bobot pada tiap kriteria yang menjadi atribut pada data, sehingga hasil dari proses inilah yang akan ditampilkan kepada user sebagai suatu rekomendasi. Adapun perhitungan metode profile matching sebagai berikut:

1. Core Factor (Faktor Utama) pada Persamaan 1 merupakan kriteria (kompetensi) yang paling penting atau menonjol atau paling dibutuhkan oleh suatu penilaian yang diharapkan dapat memperoleh hasil yang optimal [6].

$$
\mathrm{NCF}=\sum \mathrm{NC} / \sum \mathrm{IC}
$$

Keterangan:

NFC : Nilai rata-rata core factor

NC : Jumlah total nilai core factor

IC : Jumlah item core factor

2. Secondary Factor (factor pendukung) pada Persamaan 2 merupakan itemitem selain yang ada pada core factor. Atau dengan kata lain merupakan faktor pendukung yang kurang dibutuhkan oleh suatu penilaian [7].

$$
\mathrm{NSF}=\sum \mathrm{NS} / \sum \mathrm{IS}
$$

Keterangan:

$\begin{array}{ll}\text { NFS } & \text { : Nilai rata-rata secondary factor } \\ \text { NS } & \text { : Jumlah total nilai secondary factor } \\ \text { IS } & \text { : Jumlah item secondary factor }\end{array}$

3. Persamaan 3 berikut menunjukkan perhitungan Nilai Total. Nilai Total diperoleh dari prosentase core factor dan secondary factor yang diperkirakan berpengaruh terhadap hasil tiap-tiap profil [8].

$$
\mathrm{N}=(\mathrm{x}) \% \mathrm{NCF}+(\mathrm{x}) \% \mathrm{NSF}
$$

Keterangan:
N : Nilai Total dari kriteria
NFS : Nilai rata-rata secondary factor
NFC : Nilai rata-rata core factor
$(\mathrm{x}) \% \quad$ : Nilai persen yang diinputkan

4. Perhitungan penentuan ranking. Hasil Akhir dari proses profile matching adalah ranking. Penentuan ranking mengacu pada hasil perhitungan tertentu, seperti pada Persamaan 4 [9].

$$
\text { Ranking }=\mathrm{N}
$$

Keterangan :

$\mathrm{N}$ : Nilai Total

Nilai Gap yang diperoleh hasil pengurangan dari nilai minimal terhadap data tes yang digunakan. Nilai bobot yang digunakan Selisih Gap yang digunakan ditunjukkan pada Tabel 1.

Tabel 1. Keterangan Nilai Gap [10]

\begin{tabular}{cccc}
\hline No & Selisih Gap & Nilai & Keterangan \\
\hline 1 & 0 & 5 & Tidak ada selisih \\
2 & 1 & 4.5 & Kompetensi individu lebih satu tingkat \\
3 & -1 & 4 & Kompetensi individu kurang satu tingkat \\
4 & 2 & 3.5 & Kompetensi individu lebih dua tingkat \\
5 & -2 & 3 & Kompetensi individu kurang dua tingkat \\
\hline
\end{tabular}

Rekomendasi Guest House dan Villa Kota Wisata Batu... Rizky Irwan Saputra, Gita Indah Marthasari, Wildan Suharso 


\begin{tabular}{cccc}
\hline 6 & 3 & 2.5 & Kompetensi individu lebih tiga tingkat \\
7 & -3 & 2 & Kompetensi individu kurang tiga tingkat \\
8 & 4 & 1.5 & Kompetensi individu lebih empat tingkat \\
9 & -4 & 1 & Kompetensi individu kurang empat tingkat \\
\hline
\end{tabular}

Tabel 2. Bobot Kriteria

\begin{tabular}{ccc}
\hline No & Kriteria & Persentase bobot $\%$ \\
\hline 1 & Jarak & $30 \%$ \\
2 & Harga & $30 \%$ \\
3 & Fasilitas & $20 \%$ \\
4 & Akses & $20 \%$ \\
\hline & Total & $100 \%$ \\
\hline
\end{tabular}

Pada Tabel 2 merupakan bentuk persentase bobot yang digunakan dalam pemrosesan menggunakan metode profile matching, kriteria core factor mendapatkan persentase sebesar $30 \%$ dan $20 \%$ untuk secondary factor. Core factor mendapat presentase lebih banyak karena dia adalah aktor utama.

Tabel 3. Penilaian Kriteria Jarak

\begin{tabular}{cccc}
\hline Kriteria & Keterangan & Range & Skor \\
\hline \multirow{4}{*}{ Jarak } & & $0 \mathrm{~m}-1500 \mathrm{~m}$ & 5 \\
& Core Factor: & $1500 \mathrm{~m}-3000 \mathrm{~m}$ & 4 \\
& Jarak dari pengguna & $3000 \mathrm{~m}-4500 \mathrm{~m}$ & 3 \\
& Aplikasi ker tempat tujuan & $4500 \mathrm{~m}-6000 \mathrm{~m}$ & 2 \\
& & Lebih dari $6000 \mathrm{~m}$ & 1 \\
\hline
\end{tabular}

Pada Tabel 3 merupakan bentuk pembagian kriteria, range dan skor yang digunakan oleh kriteria jarak, jarak dengan skor paling tinggi 5 diperoleh jika pengguna aplikasi ini berada dalam jangkauan antara 1-1500 meter dari lokasi-lokasi yang direkomendasikan.

Tabel 4. Penilaian Kriteria Harga

\begin{tabular}{cccc}
\hline Kriteria & Keterangan & Range & Skor \\
\hline \multirow{4}{*}{ Harga } & core factor : harga & Rp 50.000-Rp 500.000 & 5 \\
& yang ditawarkan & Rp 500.000-Rp 1.500.000 & 4 \\
& penyedia jasa & Rp $1.500 .000-$ Rp 2.500.000 & 3 \\
& kepada pengguna & Rp2.500.000-Rp4000000 & 2 \\
& aplikasi & Lebih dari Rp 4000.000 & 1 \\
\hline
\end{tabular}

Pada Tabel 4 merupakan keterangan core factor pada kriteria harga berikut dengan range Harga dan skor yang diberikan pada Aplikasi.

Tabel 5. Penilaian Kriteria Fasilitas

\begin{tabular}{cccc}
\hline Kriteria & Keterangan & Range & Skor \\
\hline \multirow{4}{*}{ Fasilitas } & kantin atau penyediaan makan, \\
& kecondary factor: & kersihan, tv, kulkas, wifi, air panas, & 5 \\
& ac dan kolam renang \\
& $\begin{array}{c}\text { Item - item yang } \\
\text { menunjang Core } \\
\text { factor }\end{array}$ & kantin atau penyediaan makan, & \\
& & kebersihan, tv, kulkas, wifi, air panas & 4 \\
& & Tv, kulkas, wifi, air panas, teh kopi & 3 \\
& Tv, air panas, air minum & 2 \\
& Tv dan air minum & 1 \\
\hline
\end{tabular}

Pada Tabel 5 merupakan Secondary factor susunan range dan skor untuk kriteria fasilitas, nilai tertinggi diberikan pada penyedia layanan yang memberikan fasilitas paling banyak, fasilitas yang ditawarkan rata-rata akan memperngaruhi harga dari jasa yang ditawarkan sehingga vila atau guest house dengan layanan yang serba lengkap tentu akan memiliki tarif yang lebih tinggi.

REPOSITOR, Vol. 2, No. 6, Juni 2020: 691-700 
Tabel 6. Penilaian Kriteria Akses

\begin{tabular}{cccc}
\hline Kriteria & Keterangan & Range & Skor \\
\hline \multirow{4}{*}{ Akses } & Secondary factor: & Dapat dilalui bus pariwisata & 5 \\
& Item - item yang & Dapat dilalui mobil keluarga & 4 \\
& menunjang Core & Dapat dilalui sepedah motor & 3 \\
& factor & Jalan Kaki & 2 \\
& & Jalan rusak & 1 \\
\hline
\end{tabular}

Pada Tabel 6 merupakan secondary factor susunan penilaian kriteria akses dengan pembagian range berisi keterangan jenis kendaraan yang dapat mengakses lokasi tersebut, sehingga jika dalam range tersebut terdapat penjelasan akses ke lokasi dapat ditempuh dengan bus pariwisata maka akan mendapat skor paling tinggi, kemudian diikuti dengan akses yang lebih minim.

\section{Hasil dan Pembahasan}

\subsection{Hasil Penelitian}

Setelah tahap implementasi block program maka akan diperoleh hasil berupa interface yang tersusun dalam beberapa tampilan pada menu-menu aplikasi. Desain dari user interface yang baik dalam sebuah sistem dapat mempermudah user atau pengguna dalam menggunakan aplikasi tersebut. Interface pada aplikasi ini menggunakan bahasa pemrograman android MIT APP Inventor. Gambar 6 berikut adalah tampilan interface pada sistem yang sudah dibangun.

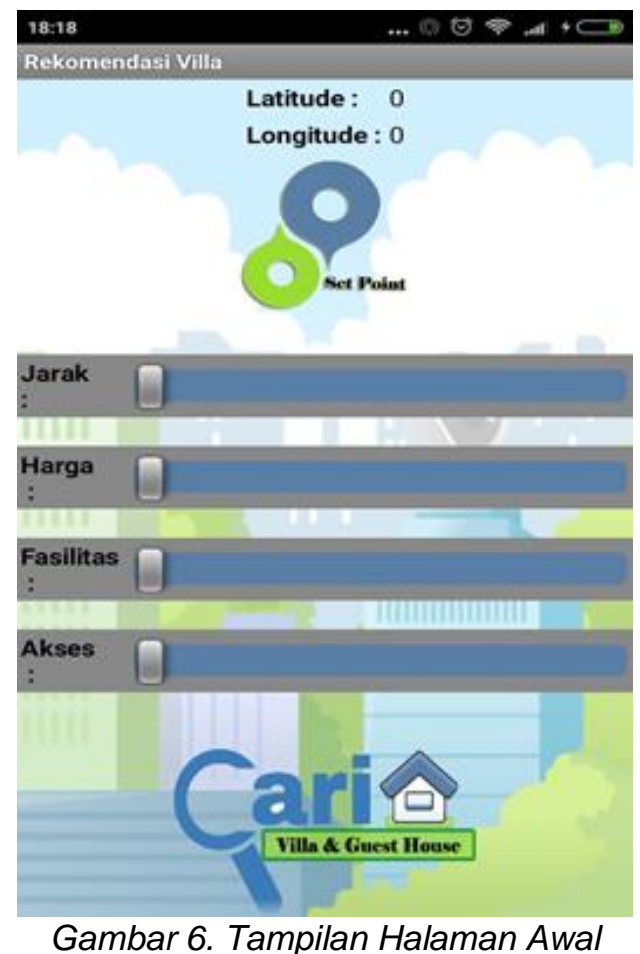

Pada Gambar 6 merupakan tampilan ini adalah halaman depan yang pertama kali diakses oleh pengguna atau user. Terdapat keterangan lokasi dengan Latitide dan Longitude, tombol Set Point untuk mengambil posisi user saat ini, slider-slider untuk menerima input kriteria dari user dan tombol cari vila untuk memproses semua input yang diterima kedalam profile matching dan dikeluarkan sebagai suatu rekomendasi kepada user.

\subsection{Hasil Pengujian}

Dari hasil pengujian pada Tabel 7 maka hasilnya adalah keseluruhan fungsional aplikasi ini baik menu atau tombol berfungsi dengan baik sesuai rancangan sistem. Sehingga dalam penggunaan tidak terjadi masalah baik saat digunakan oleh pengguna. 


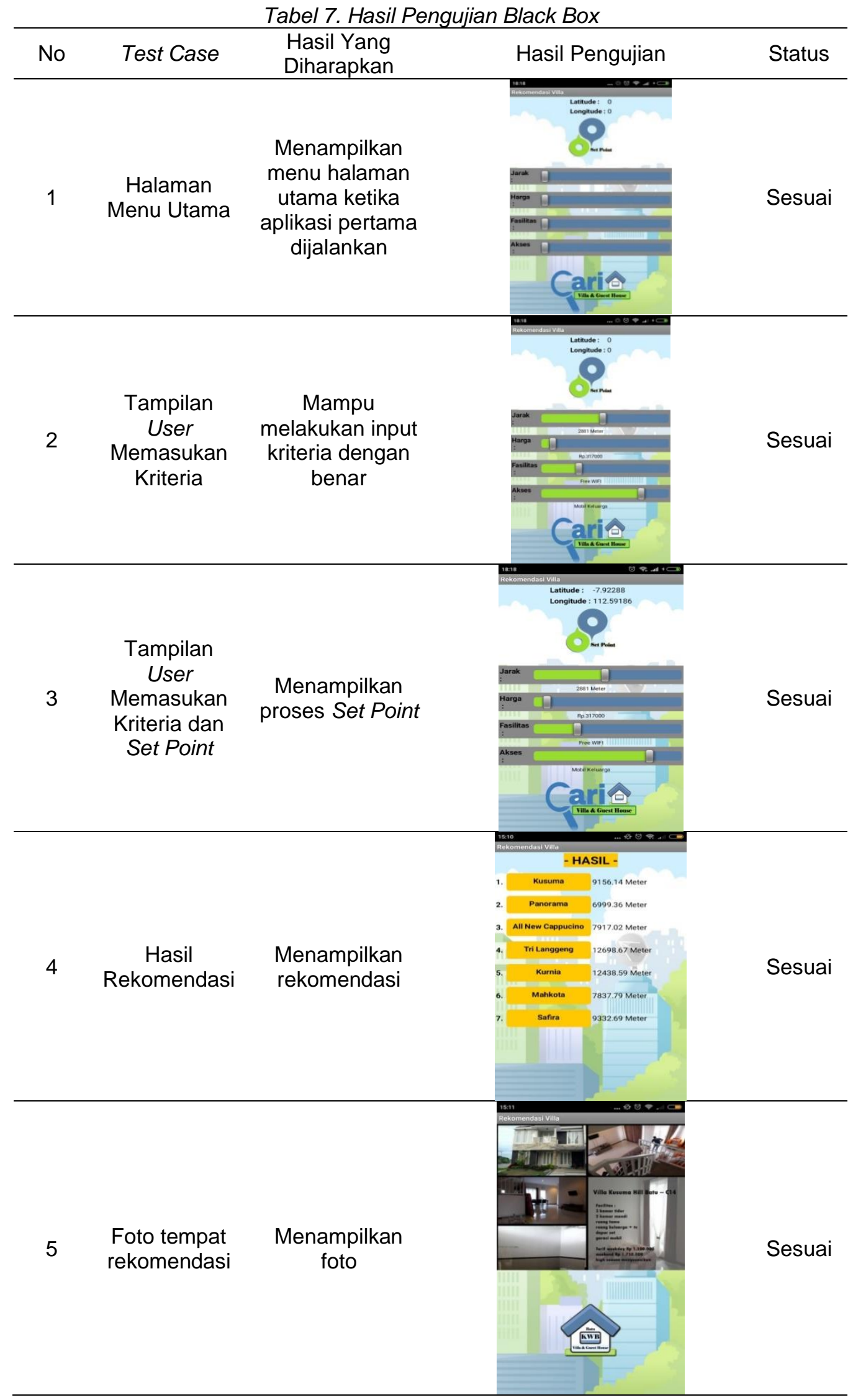


6

$\begin{array}{cc}\text { Rute ke } & \text { Menampilkan } \\ \text { tempat } & \text { foto } \\ \text { rekomendasi } & \end{array}$
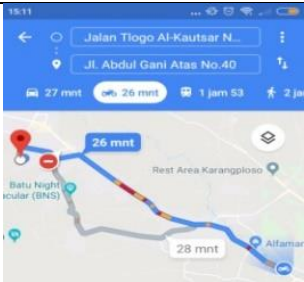

Sesuai

$26 \mathrm{mnt}(11 \mathrm{~km})$ a

it inam bonjor

\section{Kesimpulan}

Berdasarkan pengujian yang telah dilakukan dapat diambil kesimpulan yaitu aplikasi Rekomendasi Guest house dan Vila di Kota Batu berbasis Android ini mampu memberikan rekomendasi berdasarkan perhitungan profile matching dan dapat bekerja lebih baik dan terkomputerisasi.

1. Dengan menggunakan metode perhitungan profile matching pada aplikasi ini menghasilkan suatu rekomendasi kepada user berdasarkan kriteria yang mereka inginkan, sehingga hasil yang rekomendasi dikeluarkan sangat sesusai dengan keinginan user.

2. Karena pada MIT APP Inventor menyediakan akses ke Google Map API maka, sangat memungkinkan mengintegerasikan program ini dengan sistem navigasi yang berbasis Google Map API dan dibuktikan dengan pengujian blackbox yang menunjukan program dapat menunjukan koordinat hasil rekomendasi beserta rute ke tempat tersebut.

\subsection{Saran}

Untuk pengembangan perangkat lunak lebih lanjut agar hasilnya lebih baik lagi, maka ada beberapa hal yang dapat ditambahkan antara lain:

1. Aplikasi yang dibuat dapat dikembangkan lebih lanjut untuk membuat suatu sistem yang lebih baik, baik dalam penambahan cakupan tempat yang direkomendasikan maupun kriteria apa saja yang dapat dimasukan oleh pengguna aplikasi.

2. Dengan menggunakan design user interface yang lebih rapi tentunya aplikasi ini akan lebih menarik untuk digunakan, karena kebanyakan pengguna aplikasi android juga mengutamakan indahnya user interface dalam menilai kualitas suatu aplikasi.

3. Memperluas objek penelitian dengan menambahkan fitur pemesanan Villa dan Guest House.

\section{Referensi}

[1] Chairi, A., Putri, R., \& Fanani, L. 2017 Agu 30. Rekomendasi Tempat Wisata Kota Malang Menggunakan Metode Profile Matching Dan Saran Rute Menggunakan Floyd Warshall Berbasis Android. Jurnal Pengembangan Teknologi Informasi dan Ilmu Komputer. [Online] 2:5

[2] Setiawan, Cahyo. "Pembangunan Aplikasi Traveling Guide Kota Bogor Menggunakan Google MAP API." (2014).

[3] Hafsah, Mrs, Frans Richard Kodong, and Alain Julian. "Sistem Pendukung Keputusan Penentuan Hotel Dengan Menggunakan Metode Promitee dan AHP." Seminar Nasional Informatika 2011. 2011.

[4] Arisandi, Arisandi, Muh Ihsan Sarita, and S. Sagala La Ode Hasnuddin. "Sistem Penunjang Keputusan Pemilihan Hotel di Kota Kendari Berbasis Web Menggunakan Metode Fuzzy Tahani." semanTIK 2.1 (2016).

[5] Harimurti, Krisna, and Y.Sugianto. Analisis Ppengaruh Ketanggapan Karyawan, Empati Karyawan dan Kehandalan Karyawan Terhadap Kualitas Pelayanan serta Dampaknya pada Kecayaan Konsumen (Studi Pada Guest House Griya Bougenville Semarang). Diss. Fakultas Ekonomika dan Bisnis, 2013.

[6] Muqtadir, Asfan, and Irwan Purdianto. "Sistem Pendukung Keputusan (SPK) Penentuan Perjalanan Dinas Kerja Karyawan Menggunakan Metode Profile Matching (Studi Kasus Pada PT.Nusantara Turbin dan Propulsi)." Seminar Nasional Aplikasi Teknologi Informasi (SNATI). Vol. 1. No. 1. 2014. 
[7] Nashrullah, Muhammad Irfan, Gunawan Abdillah, and Faiza Renaldi. "Sistem Pendukung Keputusan Untuk Rekomendasi Promosi Jabatan Menggunakan Metode Profile Matching Dan Electre." Prosiding SNST Fakultas Teknik 1.1 (2016). [3] Irawan, Dewi \& cholissodin , 2015.

[8] Satrio Nugroho. 2016. Sistem Pendukung Keputusan Pemilihan Lokasi Objek Wisata Di Kabupaten Grobongan Menggunakan Metode Profile Matching.

[9] Darmawan, A. S. (2012). Pemilihan Beasiswa Bagi Mahasiswa STMIK Widya PratamaDengan Metode Profile Matching. Jurnal IImiah ICTech, 10(1), 1-5.

[10] A. T. Susilo."Penerapan Metode Profile Matching pada Sistem Pendukung Keputusan Pemilihan Ketua Program Studi."JUITA p-ISSN: 2086-9398; e-ISSN: 2579-8901; Volume V, Nomor 2, November 2017. 